\title{
EVALUATION OF THE SLOPE-VOLUME METHOD AS AN INDEX OF PULMONARY BLOOD VOLUME*
}

\author{
By YANG WANG, $\dagger$ JOHN T. SHEPHERD $\ddagger$ AND ROBERT J. MARSHALL $\S$
}

(From the Mayo Clinic and Mayo Foundation,\| Rochester, Minn.)

(Submitted for publication August 3, 1959; accepted November 12, 1959)

The Stewart-Hamilton method (1) for measurement of blood volumes from indicator dilution curves has been validated in both theory (2) and practice (3), provided that certain conditions are met.

Measurement of the pulmonary blood volume by the Stewart-Hamilton method would entail injection of indicator into the main pulmonary artery and sampling from the left atrium. However, while insertion of a catheter into the left atrium of the dog is technically feasible, an unknown portion of the left atrial volume will be included in the measurement. A more serious objection is the evidence that the process of mixing of dye with blood in the left atrium is incomplete $(4,5)$, and thus one of the conditions for valid application of the Stewart-Hamilton method is not fulfilled. The interposition of the left ventricle and aortic valve is essential to achieve uniform cross-sectional distribution of indicator at the sampling site $(6,7)$. Therefore, it is necessary to place the tip of the sampling catheter in the aortic root distal to the aortic valve. The blood volume between the site of injection (main pulmonary artery) and the sampling site thus comprises both lungs and the chambers of the left side of the heart. This is probably the nearest approximation to the pulmonary blood volume that can be measured at present by the method.

Newman, Pearce and associates $(8,9)$, using a different analysis of indicator dilution curves, introduced the concept that the "slope volume" provides a measurement or index of the pulmonary blood volume. The slope volume is a func-

* This investigation was supported in part by Research Grant no. H-4744 from the National Institutes of Health, Public Health Service, Bethesda, Md.

$\dagger$ Minnesota Heart Association Fellow in Physiology, Mayo Foundation.

$\ddagger$ Section of Physiology.

§ Research Assistant in Physiology, Mayo Foundation.

|| The Mayo Foundation, Rochester, Minn., is a part of the Graduate School of the University of Minnesota. tion of the blood flow and the rate of diminishing concentration of the indicator during the phase between the peak concentration and commencing recirculation, hereinafter referred to as the "disappearance slope." The concept of slope volume has been derived from both theoretic reasoning and from demonstrations in model systems which have shown that, in a series of perfect mixing chambers, the largest single chamber will dominate the disappearance slope of the dilution curve, the other chambers influencing this slope only in the initial phase. The original assumption of Newman and his co-workers was that the lungs and heart chambers constitute such a series and that, therefore, the lungs, which presumably have the largest blood volume, should dominate the disappearance slope of the indicator dilution curve. More recently, Emanuel, Lacy and Newman (10) have defined the slope volume as "a volume of blood which would produce the exponential slope obtained if the flow mixed with all of the volume as if the volume were contained in a single completely mixed chamber (or a chamber made of parallel channels, all having the same ratio of flow to mixing volume)."

In the Stewart-Hamilton method for deriving the blood volume of the lungs and the left side of the heart, changes in pulmonary blood volume might well be obscured by simultaneous but opposite changes in blood volume in the left side of the heart. The slope volume, however, by providing an estimate of the blood volume of the lungs alone, might be expected to avoid such uncertainties. Therefore, the present studies were designed to test the validity of the slope volume as an index of the volume of blood in the lungs.

\section{METHODS}

Sixteen mongrel dogs weighing 14 to $25 \mathrm{~kg}$ were used. In 11 trained dogs, cardiac catheters were introduced under local anesthesia and in the remainder, under sodium pentobarbital anesthesia. A catheter, used for 

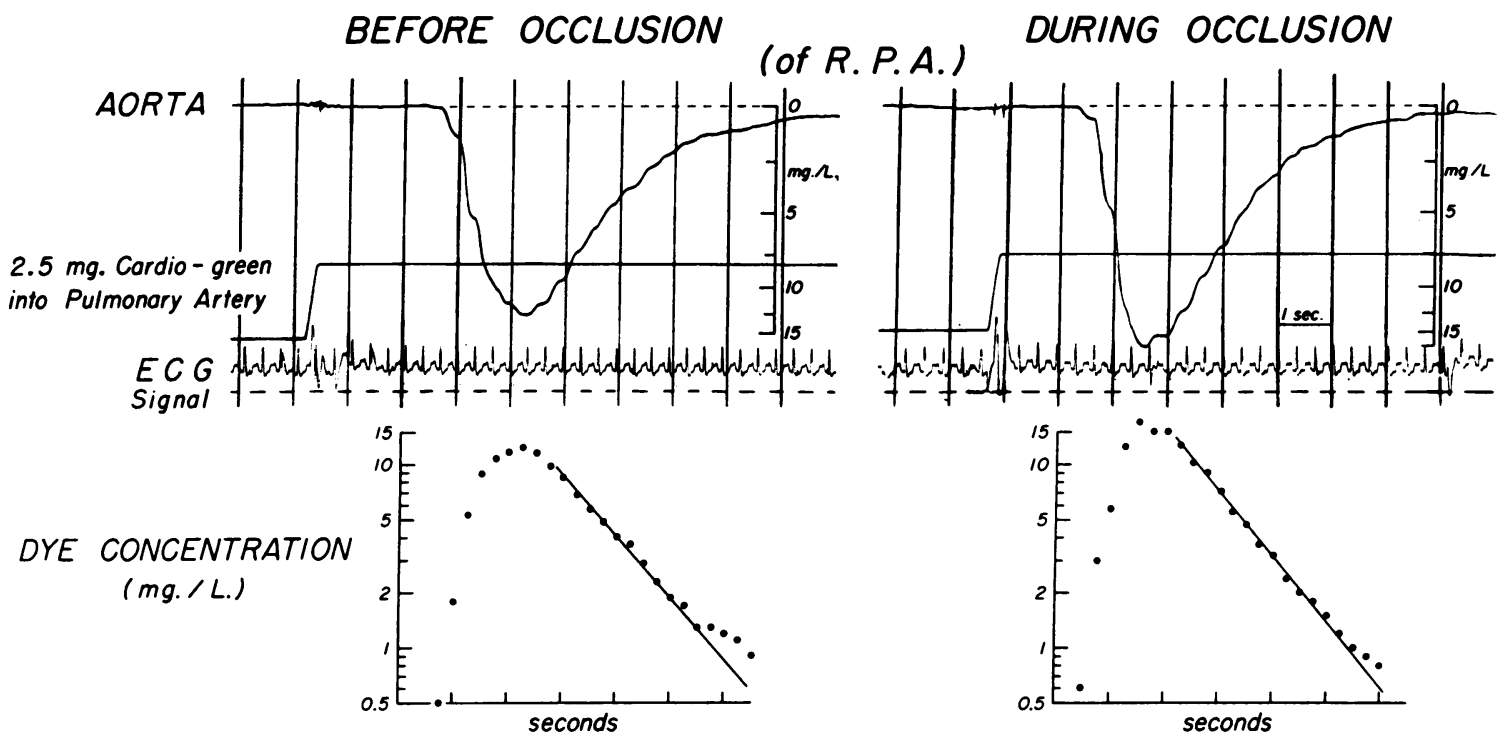

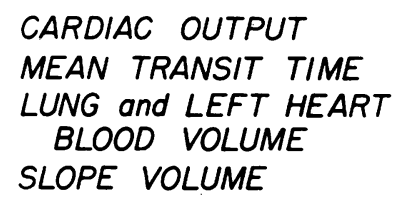

$4.4 \mathrm{~L} . / \mathrm{min}$.

4.4 seconds

$320 \mathrm{ml}$.

$92 \mathrm{ml}$.
$4.2 \mathrm{~L} . / \mathrm{min}$.

3.4 seconds

$235 \mathrm{ml}$.

$85 \mathrm{ml}$.

Fig. 1. UPPER PANEL. INDICATOR DILUTION CURVES BEFORE AND DURING OCCLUSION OF THE RIGHT PULMONARY ARTERY IN A DOG WEIGHING $19.8 \mathrm{~kg}$. The recirculation portions of the curves are not included. The deflection of the syringe line indicates the instant and magnitude of the injection. Note the shortening of the mean transit time during arterial occlusion.

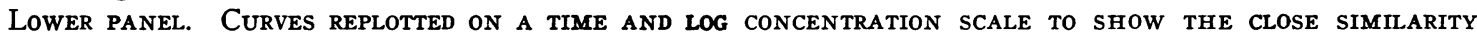
OF THE DISAPPEARANCE SLOPE OF BOTH CURVES.

injections of the indicator, was introduced via the external jugular vein into the pulmonary artery so that its tip lay just distal to the pulmonary valve. A $40 \mathrm{~cm}$ catheter having a dead space of $0.4 \mathrm{ml}$ was inserted into the left ventricle via the carotid artery and withdrawn until its tip lay just above the aortic valve; this was used for sampling. The positions of the catheter tips were checked by fluoroscopy and manometry during introduction and at intervals throughout the observations. In a group of separate studies, the femoral artery was used as the sampling site. In 2 dogs, an additional no. 5 French catheter with a balloon about 4 to $6 \mathrm{~cm}$ from the tip was introduced into the pulmonary artery. The catheter was advanced until its tip became impacted in a distal branch; in this way, the position of the balloon remained fixed. The balloon could be inflated to occlude the right or left pulmonary artery or lobar branches thereof. The effectiveness of such occlusion was confirmed by angiograms made after injection of a 70 per cent solution of sodium acetrizoate (Urokon Sodium).

An indocyanine dye (cardio-green ${ }^{1}$ ) was used as the

${ }^{1}$ Kindly supplied by Hynson, Westcott and Dunning, Baltimore, Md. indicator at a concentration of $1.25 \mathrm{mg}$ per $\mathrm{ml}$ in doses of 1.5 to $2.0 \mathrm{mg}$. Particular attention was paid to the characteristics of the injecting, sampling and recording systems, since determination of blood volume by the Stewart-Hamilton method depends especially on accurate measurement of the time components of the indicator dilution curve. Injections were made by a pneumatic syringe capable of delivering $1.0 \mathrm{ml}$ of dye solution in 0.10 second. An automatic signaling device recorded the instant and volume of each injection (Figure 1). The dead space of the catheter and syringe system was kept filled with dye between successive injections. A densitometer ${ }^{2}$ having a dead space of $0.1 \mathrm{ml}$ was connected to the aortic catheter which had a dead space of $0.4 \mathrm{ml}$. When the method of Fox, Sutterer and Wood (11) for assaying dynamic response characteristics was

2 This densitometer was developed by the Section of Engineering of the Mayo Clinic. It is similar to Model $\mathrm{XC}-100 \mathrm{~A}$ manufactured by the Waters Corporation, Rochester, Minn., but it has a slightly larger internal diameter to permit high flows. The light-sensitive element is a phototube with an extremely high internal resistance. A power amplifier (a cathode follower) is used to obtain current, which is fed into a recorder. 


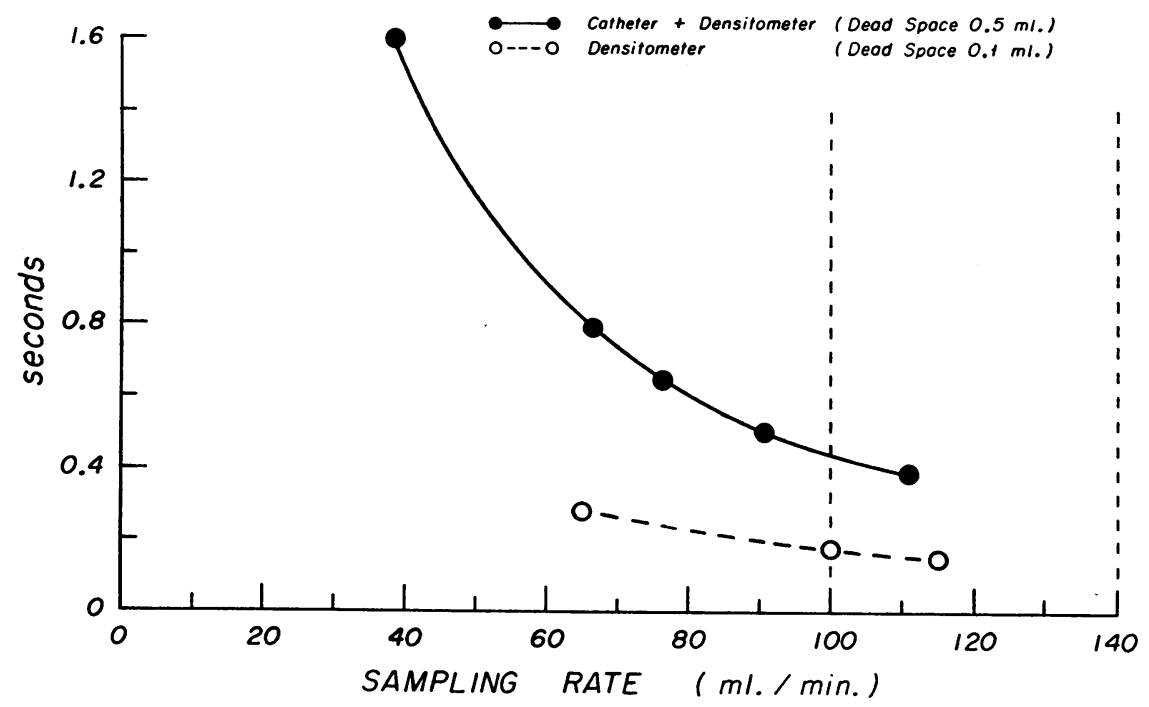

Fig. 2. DyNAMiC RESPONSE OF CATHETER-DENSITOMETER-GalvaNOMETER SYSTEM. The time required to attain 90 per cent response to a "square wave" of dye (cardiogreen) in blood is plotted against the sampling rate.

used, this densitometer-galvanometer system responded to a "square wave" input of cardio-green dye in blood by reaching 90 per cent of its maximal deflection in 0.20 second at the sampling rates of 100 to $120 \mathrm{ml}$ per minute used throughout the studies (Figure 2). These sampling rates were achieved by use of vacuum suction at about $1.5 \mathrm{~kg}$ per square centimeter. A time correction was made in each instance for the mean transit time of indicator through the sampling system at the particular sampling rate used.

The indicator dilution curves obtained by this system show step functions (Figure 1). These are synchronous with the heart beat and represent changes in the concentration of dye at the aortic root during successive ejections of the left ventricle. Such curves contrast

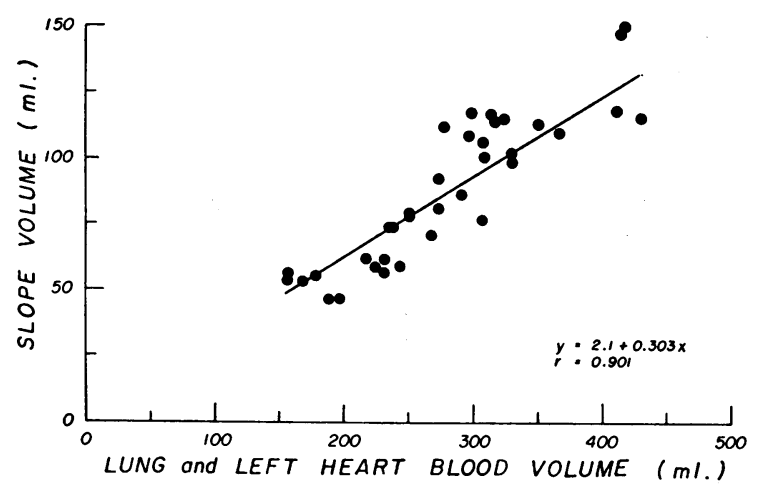

Fig. 3. Slope volume plotted AGainst CORRESPondING VOLUME OF BLOOD IN LUNGS AND LEFT SIDE OF HEART (36 DETERMINATIONS IN 16 DOGS). Note the correlation but the large systematic difference. with the smoothly contoured curves obtained by means of sampling and recording systems that have slower dynamic response characteristics.

The volume between the injection and sampling sites was calculated by the Stewart-Hamilton formula (1), and the slope volume was determined by the method of Newman and co-workers (8). Calibration curves were obtained for each dog by drawing various known concentrations of dye in blood through the densitometer. In many experiments, dilution curves were obtained for blood at the start of the experiment (free of dye) and at the end of the experiment (with residual background dye). The calibrations usually were slightly different, as would be expected. However, the difference was never great, since cardio-green disappears from circulating blood much more quickly than does T-1824. When a difference was present, the calibrations were interpolated for intermediate dilution curves.

\section{RESULTS}

The pulmonary artery was used as the injection site and the aortic root as the sampling site in 36 determinations in the 16 dogs. Figure 3 shows the blood volumes, as calculated by the Stewart-Hamilton method, plotted against the corresponding slope volumes. There is a correlation $(R=0.9)$ but also a large systematic difference. The combined volume in the lungs and left side of the heart averaged $156 \mathrm{ml}$ (SE 3.9) per $10 \mathrm{~kg}$ of body weight, whereas the slope volume averaged $48 \mathrm{ml}$ (SE 1.7 ) per $10 \mathrm{~kg}$ of body 


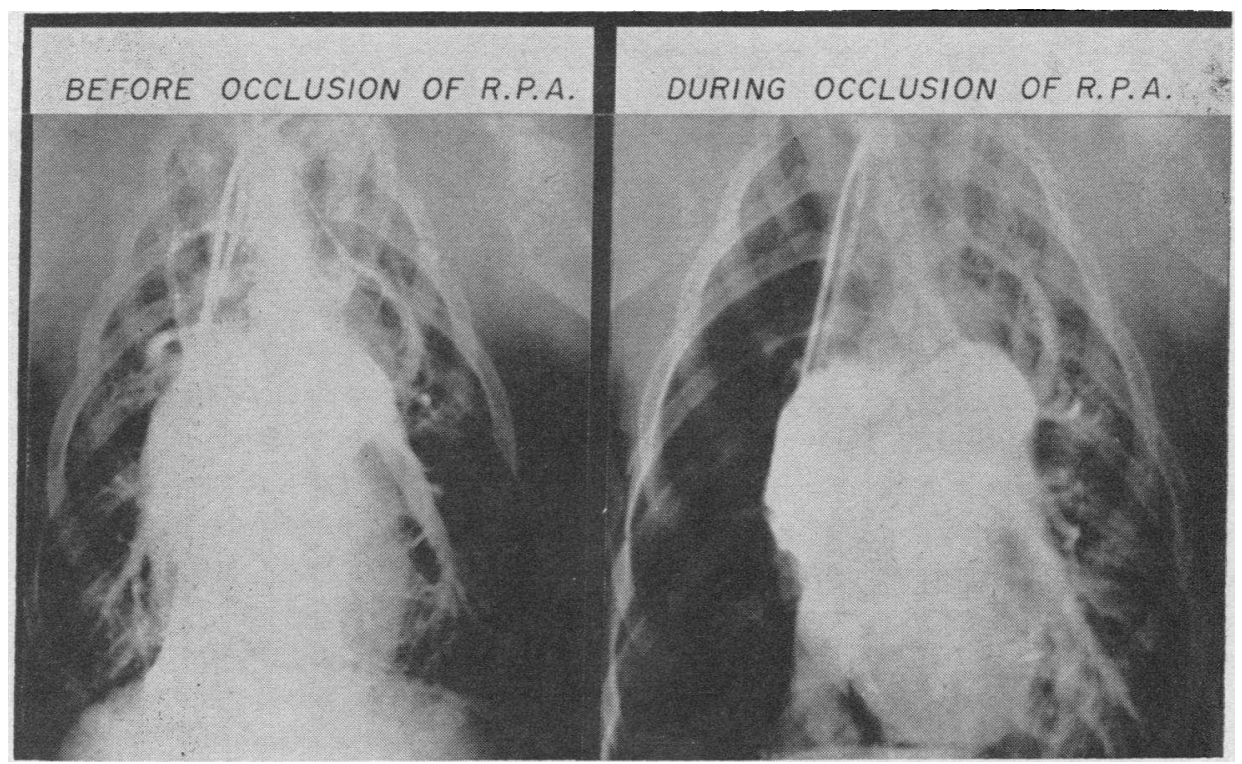

Fig. 4. ANgiograms after injection of a 70 PER CENT SOlution of SOdiUm ACETRIzoAte INTO THE RIGHT ATRIUM. Before occlusion of the right pulmonary artery, the pulmonary vessels of both lungs are clearly visualized. During occlusion, there is no filling of the vessels of the right lung.

weight. It is of interest that Dow (12) found a practically identical ratio, namely 0.31 , between slope volume and central volume in dogs. Thus, the slope volume is about 30 per cent of the blood volume in the lungs and left side of the heart. Some data obtained in our laboratory suggest that the lungs account for about two-thirds of the combined volume (13). This would make the slope volume about 45 per cent of the pulmonary blood volume.

These volumes were compared with nine determinations in seven dogs in which the femoral artery was used as the sampling site. Under these circumstances, the volume by the StewartHamilton method averaged $227 \mathrm{ml}$ (SE 15.9) per $10 \mathrm{~kg}$ of body weight, while the slope volume averaged $50 \mathrm{ml}$ (SE 2.3) per $10 \mathrm{~kg}$ of body weight. The increase in the former volume was consistent with the different extent of the vascular bed included between the injection and sampling sites (13). The slope volume, however, was strikingly constant, a finding previously reported by Pearce, McKeever, Dow and Newman (9).

As already noted, the volume of the pulmonary vascular bed in two dogs was acutely and inter- mittently reduced by inflation of a balloon in the pulmonary artery. In one of these animals, the right pulmonary artery was occluded, the com-

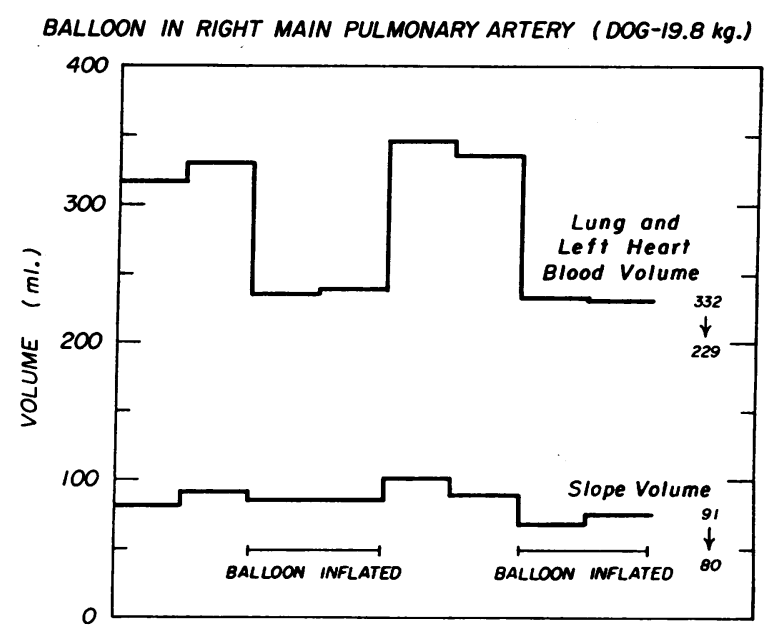

Fig. 5. Changes in SLope volume and in volume of BLOOD IN LUNGS AND LEFT SIDE OF HEART WITH INTERMITTENT OCCLUSION OF RIGHT PULMONARY ARTERY BY BALLOON-TIPPED CATHETER. The occlusion in each instance lasted from 7 to 10 minutes. In both this figure and in Figure 6 , note the pronounced and reproducible changes in the blood volume of the lungs and left side of the heart in contrast to the incommensurate changes in slope volume. 


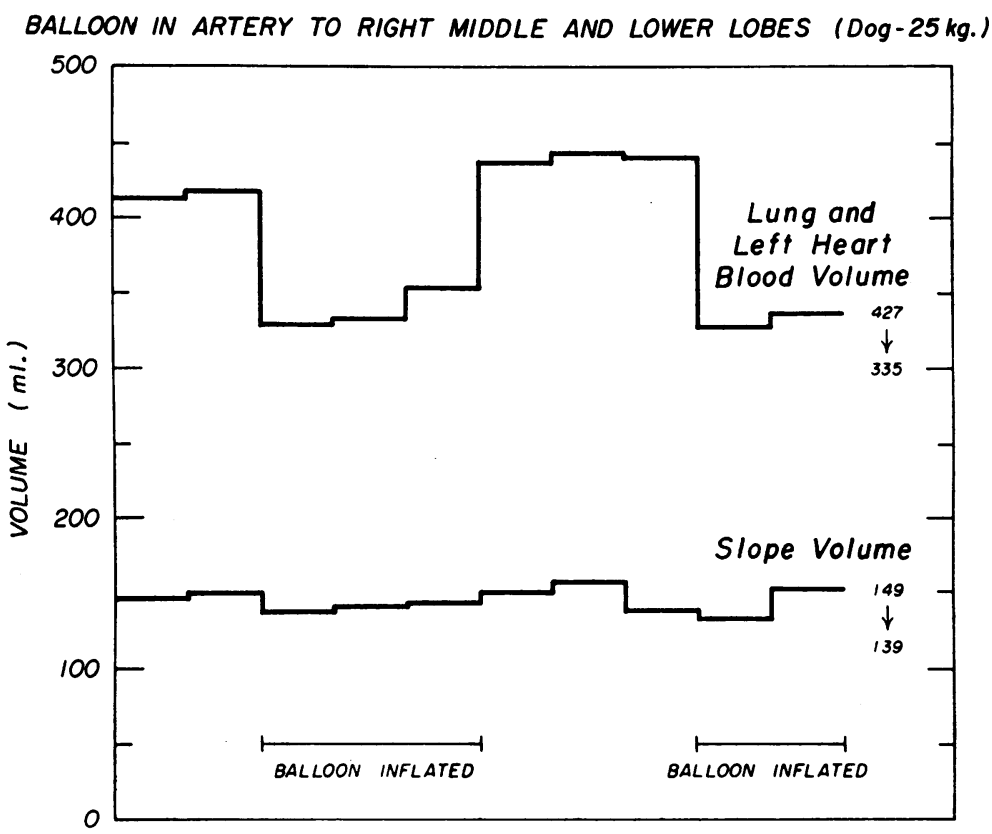

Fig. 6. Changes in SLope volume and in volume of blood in LUNGS AND LEFT SIDE OF HEART WITH INTERMITTENT OCCLUSION OF ARTERIES TO LOWER HALF OF RIGHT LUNG. The occlusion in each instance lasted from 7 to 10 minutes.

pleteness of the occlusion being confirmed by angiography (Figure 4). During occlusion, the cardiac output either remained unchanged or showed a modest decrease. These results are similar to the findings of Brofman (14) in normal man. However, the mean transit time of the indicator was reduced by about one-third (Figure 1 ). Since the volume of blood in the lungs and left side of the heart is the product of the cardiac output and the mean transit time, this volume was reduced by about one-third, the average volume decreasing from 332 to $229 \mathrm{ml}$ (Figure 5). Volumes measured immediately on occlusion and five minutes later were similar. However, the slope volume was only slightly affected by the occlusion, the average volume decreasing from 91 to 80 $\mathrm{ml}$ (Figure 5). In the other dog, the lobar arteries to the lower half of the right lung were occluded, as confirmed by angiography. There was a corresponding decrease in the volume of blood in the lungs and left side of the heart of about one-fifth (427 to $335 \mathrm{ml}$ ), again with no consistent change in the slope volume, the average of which decreased from 149 to $139 \mathrm{ml}$ (Figure 6$)$. The procedure was repeated many times and yielded reproducible results (Figures 5 and 6 ).
DISCUSSION

The Stewart-Hamilton method depends on good mixing of the indicator with blood at the injection and sampling sites and also on constant flow during the period of observation. The first of these requirements is best fulfilled by injecting into the pulmonary artery and sampling from the aortic root $(6,7)$, as was done in these studies. The second requirement is not fulfilled, since flow through the aortic valve is not constant but pulsatile. That this theoretic objection may not be important in practice is suggested by the recent work of Schlant and associates (3), who found close agreement in measurement of the "central blood volume" in dogs by the Stewart-Hamilton method and by a technic using erythrocytes labeled with radiochromium $\left(\mathrm{Cr}^{51}\right)$.

The Stewart-Hamilton method makes no assumptions regarding the nature of blood flow through the lungs and is, therefore, valid whether such flow be laminar or turbulent. In contrast, the slope-volume method is based on the proposition that the lungs and heart chambers are a series of perfect mixing chambers. It is doubtful if the lungs can be so regarded (15-17). Theoretically, 
movement through a capillary bed such as that of the lungs provides random scattering and longitudinal dispersal of the particles of dye rather than mixing. Sheppard and Savage (15) and Sheppard (16) have shown that the problem is more akin to the "random walk." Only when the dispersing effect is not too great can an approximately log-normal distribution in time of the outflowing dye be predicted, and this condition does not obtain in the large pulmonary capillary bed. Parrish, Hayden, Garrett and Huff (17) studied pulmonary transfer characteristics with radioisotope dilution technics, using an analog computer in such a way that both transport delay and dispersion could be varied independently. They found that the vessels of the lungs behave as a system with linear flow and not as a mixing pool. Thus, it appears that the lungs cannot achieve the perfect and instantaneous mixing that is the chief assumption on which the slope-volume method is based.

It has been proposed recently that the increase in slope volume in mitral regurgitation indicates an increase in pulmonary blood volume or "effective mixing volume" (10). However, in mitral regurgitation, in addition to an enlarged upstream chamber, a to-and-fro flux of dye particles occurs across the incompetent valve, which in itself can spread the indicator dilution curve, decrease the disappearance slope, and thus increase the slope volume (18). The fact that the disappearance slope can be plotted semilogarithmically to yield a straight line is no guarantee that the disappearance slope is a single exponential function (19). It has become clear, through the use of sampling and recording systems with high dynamic response characteristics, that indicator dilution "curves" show step-like alterations in concentration corresponding to successive ventricular ejections (Figure 1), particularly when a central sampling site is used (20). Thus, when points are replotted on a semilogarithmic scale at short intervals of time, such as 0.5 second, they do not fall along a straight line, although the general trend is linear. In the present experiments, we constructed the best possible rectilinear fit through these points, designating this as the "slope." The absence of a completely smooth slope, which becomes evident when systems with high dynamic response characteristics are em- ployed, is in itself an objection to the use of this parameter as a measure or an index of an intravascular volume.

As already noted, under the conditions of our studies the slope volume is about 30 per cent of the blood volume of the lungs and left side of the heart. Previous observations have suggested that about two-thirds of the blood volume between the pulmonary and aortic valves is contained in the lungs. Thus, as mentioned earlier, the slope volume is probably about 45 per cent of the total pulmonary blood volume. When the sampling site was changed from the aortic valve to the femoral artery, only slight changes in the slope volume were observed that were incommensurate with the changes in actual volume included between the two sites. These results could be interpreted as supporting the contention that the slope volume measures a volume directly related to the pulmonary blood volume. If so, a pronounced reduction in the slope volume would be anticipated after occlusion of one of the pulmonary arteries or branches thereof. However, such a reduction could not be demonstrated. It might be held that occlusion of the right pulmonary artery resulted in redistribution of blood, so that the left lung now contained an increased quantity of blood; this was not borne out by the concomitant Stewart-Hamilton calculations, which showed consistent reduction in this volume during periods of occlusion.

Thus, the slope volume neither gives a measurement of the volume of blood within the lungs nor consistently reflects the magnitude of changes induced therein.

\section{SUMMARY}

Studies were carried out to test the validity of the Newman slope-volume method as an index or measurement of the volume of blood in the lungs. Indocyanine (cardio-green) dye was injected into the pulmonary artery of the dog, and indicator dilution curves were inscribed at the aortic root using a densitometer with a high frequency response. Sampling was from the aorta rather than the left atrium to ensure adequate mixing of the dye with blood. The StewartHamilton method was used to derive the volume of blood in the lungs and the chambers of the left 
side of the heart; the Newman method was used to calculate the slope volume.

In 36 determinations in 16 dogs, the volume of blood in the lungs and left side of the heart was $156 \mathrm{ml}$ (SE 3.9) per $10 \mathrm{~kg}$ of body weight, whereas the slope volume was $48 \mathrm{ml}$ (SE 1.7) per $10 \mathrm{~kg}$ of body weight. Thus, the slope volume is about 30 per cent of the volume in the lungs and left side of the heart and it is probably about 45 per cent of the pulmonary blood volume.

With repeated temporary occlusion of the right main pulmonary artery, the volume of blood in the lungs and left side of the heart decreased from an average of 332 to $229 \mathrm{ml}$, while the average slope volume decreased from 91 to $80 \mathrm{ml}$. With occlusion of the arteries to the lower half of the right lung, the former volume decreased from 427 to $335 \mathrm{ml}$, while the latter decreased from 149 to $139 \mathrm{ml}$.

With the assumption that the Stewart-Hamilton method is valid, it appears that the slope volume neither gives a measurement of the volume of blood in the lungs nor reflects the magnitude of changes induced therein.

\section{ACKNOWLEDGMENT}

The authors are indebted to Dr. José GonzalezFernandez for his helpful discussions on the mathematical theory of indicator dilution curves.

\section{REFERENCES}

1. Hamilton, W. F., Moore, J. W., Kinsman, J. M., and Spurling, R. G. Studies on the circulation. IV. Further analysis of the injection method, and of changes in hemodynamics under physiological and pathological conditions. Amer. J. Physiol. 1932, 99, 534.

2. Meier, P., and Zierler, K. L. On the theory of the indicator-dilution method for measurement of blood flow and volume. J. appl. Physiol. 1954, 6, 731.

3. Schlant, R. C., Novack, P., Kraus, W. L., Moore, C. B., Haynes, F. W., and Dexter, L. Determination of central blood volume. Comparison of Stewart-Hamilton method with direct measurements in dogs. Amer. J. Physiol. 1959, 196, 499.

4. Silver, A. W., Kirklin, J. W., and Wood, E. H. Demonstration of preferential flow of blood from inferior vena cava and from right pulmonary veins through experimental atrial septal defects in dogs. Circulat. Res. 1956, 4, 413.

5. Bowes, D. E., Kirklin, J. W., and Swan, H. J. C. The hemodynamic effects of large atrial septal de- fects: An experimental study. J. thorac. Surg. 1957, 33, 350.

6. van der Feer, Y. The measurement of circulation time by means of an indicator. Phys. in Med. Biol. 1958, 3, 157.

7. Peterson, L. H., Helrich, M., Greene, L., Taylor, C., and Choquette, G. Measurement of left ventricular output. J. appl. Physiol. 1954, 7, 258.

8. Newman, E. V., Merrell, M., Genecin, A., Monge, C., Milnor, W. R., and McKeever, W. P. The dye dilution method for describing the central circulation: An analysis of factors shaping the timeconcentration curves. Circulation 1951, 4, 735.

9. Pearce, M. L., McKeever, W. P., Dow, P., and Newman, E. V. The influence of injection site upon the form of dye-dilution curves. Circulat. Res. 1953, 1, 112.

10. Emanuel, R. W., Lacy, W. W., and Newman, E. V. Relative effects of heart chambers, lungs, and mitral insufficiency on the shape of indicator dilution curves. Circulat. Res. 1959, 7, 141.

11. Fox, I. J., Sutterer, W. F., and Wood, E. H. Dynamic response characteristics of systems for continuous recording of concentration changes in a flowing liquid (for example, indicator-dilution curves). J. appl. Physiol. 1957, 11, 390.

12. Dow, P. Dimensional relationships in dye-dilution curves from humans and dogs, with empirical formula for certain troublesome curves. J. appl. Physiol. 1955, 7, 399.

13. Marshall, R. J., Wang, Y., and Shepherd, J. T. Components of the "central" blood volume in the dog. Circulat. Res. 1960, 8, 93.

14. Brofman, B. L. Unilateral pulmonary artery occlusion in Intra Vascular Catheterization, H. A. Zimmerman, Ed. Springfield, Illinois, Charles C Thomas, 1959.

15. Sheppard, C. W., and Savage, L. J. The random walk problem in relation to the physiology of circulatory mixing. Physiol. Rev. 1951, 83, 489.

16. Sheppard, C. W. Mathematical considerations of indicator dilution techniques. Minn. Med. 1954, 37, 93.

17. Parrish, D., Hayden, D. T., Garrett, W., and Huff, R. L. Analog computer analysis of flow characteristics and volume of the pulmonary vascular bed. Clin. Res. 1959, 7, 127.

18. Hoffman, J. I. E., and Rowe, G. G. Some factors affecting indicator dilution curves in the presence and absence of valvular incompetence. J. clin. Invest. $1959,38,138$.

19. Dow, P. Estimations of cardiac output and central blood volume by dye dilution. Physiol. Rev. 1956, 36, 77.

20. Edwards, A. W. T., Cheesman, R. J., and Wood, E. H. Configuration of indicator-dilution curves recorded from the central circulation of the dog in relation to dynamic response of the sampling system (abstract). Physiologist 1959, 2, no. 3, 35. 